\title{
Dental treatment of twin monozygotic brothers with fragile $X$ syndrome
}

\author{
Flavia Melo Meira, Luis Candido Pinto Silva, Regina Haddad Rezek Ferreira, \\ Roberval Almeida Cruz*
}

Department of Dentistry, PUC Minas, Belo Horizonte, Brazil; *Corresponding Author: flavia meira@yahoo.com.br; lucan1@terra.com.br; haddadrezek@terra.com.br; roberval@pucminas.br

Received 3 August 2010; revised 12 August 2010; accepted 26 August 2010.

\begin{abstract}
Fragile $X$ syndrome (FXS) is the main cause of inherited mental retardation and is the result of transcriptional silencing of the fragile $X$ mental retardation gene FMR1. An absence of the associated protein FMRP leads to the deregulation of many genes, which results in phenotypes of Attention-Deficit Hyperactivity Disorder (ADHD), anxiety, epilepsy and autism. The aim of this article is to report the clinical case of twin siblings affected by FXS and to describe the procedures for dental treatment with intravenous sedation. Information regarding the characteristic manifestations of FXS not only aided in the handling of the patients but also enabled us to develop clinical programs to promote and maintain oral health using individualized and specific dental procedures.
\end{abstract}

Keywords: Syndromes Head and Neck/cleft Lip and Palate; Fragile $X$ Syndrome; Pain

Control/Sedation; Oral Medicine

\section{INTRODUCTION}

Fragile X syndrome (FXS) is the most commonly inherited form of mental disability in men and to a lesser extent in women due to the presence of a single chromosome $\mathrm{X}$. Its prevalence is estimated to be 1:4000 in men and 1:6000 in women. It is the most frequent manifestation of intellectual impairment after Down syndrome, a main cause of hereditary mental retardation [1-6].

FXS's name is derived from an existing constriction in the long arm (q) of chromosome $\mathrm{X}$ in the area of the mutated gene FMR1 (Fragile X Mental Retardation 1). The protein coded by this gene is called FMRP (Fragile $\mathrm{X}$ Mental Retardation Protein). FMRP was sequenced in 1991, and it is predominantly expressed in the brain and gonads. Although its exact function is still unknown, its properties and location suggest that it is involved in regulating the transport, stability and translation of some mRNAs. FMR 1 may affect the mRNAs of proteins by activating or inactivating their production $[7,8]$. Most of the mRNAs that are identified as targets of FMR1 are involved in some aspect of synaptic structure, and their corresponding proteins are involved in the formation of memory and learning. It is very probable, therefore, that the cause of the mental deficiency produced by FXS is due to an absence of FMRP in the synaptic junction [9].

The carriers of this condition usually do not show phenotypic manifestations, but they do have the risk of generating affected offspring. In general, the pre-mutations can become complete mutations remaining unknown the accurate time when this happens, may be during the gametogenesis or during the start of embryonic development. Thus women with 55-200 CGG repeats have a greater risk of transmission due to allelic instability. When the mutation exceeds 200 repetitions, it is called a full mutation and this causes methylation of the promoter region with the consequent repression of the gene FMR-1. This gene repression then results in the absence of protein FMRP expression. As a consequence, mental retardation and other clinical characteristics of FXS are manifested [10,11].

Among the most common physical characteristics, besides the mental retardation of variable intensity, are large everted ears, a long face, hyper-extendable articulations, short and thick fingers and macro orquidism. Also described are wide eyelids rifts, a large skull relative to the trunk, epicanthic pleats, eyes that squint, hypotonic muscles, short-sightedness, a prolapse of the mitral valve, dilation of the aorta, suction calluses on the hands and fingers, flat feet and a unique palm line [12-14]. To a lesser extent, symptoms of neurological problems have been reported, such as hyperreflexia, nystagmus and epilepsy [15]. The characteristics of dental interest are mandibular prognathism, macroquilia, 
macroglossia, ogival palate and alterations in the dental enamel. These symptoms cause dental tissue exposition, and this condition cannot be attributed to physiological attrition [16].

Patients with the FXS have very peculiar personalities. Some disturbances of behavior that have been reported include shyness, anxiety, panic and violent attacks, defense or avoidance of tactile contact, explicit memory, a sense of humor and an excellent ability to imitate. FXS patients are very attached to their immediate environment, and some cannot filter noise and light and such stimuli can trigger hyper-activity symptoms, attention deficit and impulsiveness. The sensory system in these individuals does not always respond appropriately, and they can react in a negative way to some types of tactile stimuli. Certain stimuli can be responsible for the exhibition of autistic behavior, such as turning the hands and biting them, stereotypical movement of the limbs and poor visual contact. Speech is severely impaired, and the development of language is limited until approximately two or three years of age. They possess little verbal communication skills and poor articulation of words. Speech is exhibited in a noisy way, in an irregular rhythm and in an expressive tone to emphasize emotions or to reinforce the meanings of words [17].

Recent studies report a new condition that has been called Fragile X-associated Tremor/Ataxia Syndrome (FXTAS). This new classification includes a group of neurological symptoms typically associated with elderly men who also carry the pre-mutation for the gene FMR 1 . The alterations in behavior include tremor, walking and balance difficulty, anxiety and loss of memory [18,19].

The aim of this article is to report the clinical case of twin siblings affected by FXS and to describe the procedures for dental treatment with intravenous sedation.

\section{CASE REPORT}

Genetic information might have health and reproductive implications for the patient and their family members. The responsibility for communicating this information within families generally lies with the patient or genetic counselor [20]. In this way, 13-year-old male (Figure 1)

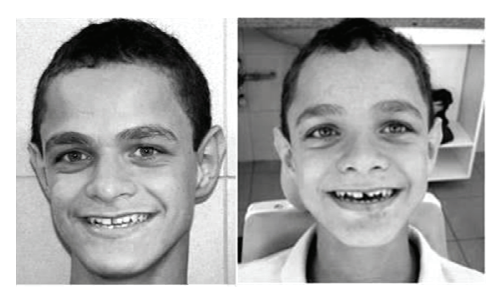

Figure 1. Facial aspect of twin siblings with the fragile $\mathrm{X}$ syndrome. monozygotic twins with fragile $\mathrm{X}$ syndrome were referred for treatment to the Dental Clinic for Patients with Special Needs at the Catholic University of Minas Gerais.

At admission, the mother indicated that the period of gestation proceeded normally. In the first year of the children's lives, a delay in neuropsychomotor development was detected. The children were hyperactive and began walking at around 2 years of age. At 7 years of age, they were referred to Sarah Kubitschek Hospital for genetic analysis, and at that time, they were diagnosed with fragile $\mathrm{X}$ syndrome.

The behavior of the twins could be defined with sufficient clarity. At first, it was observed that the twins had a degree of moderate mental retardation, hyperactivity, poor visual contact, echolalia, and problems in speech particularly in the pronunciation of words. According to the mother, they exerted the majority of their activities independently, learned slowly, showed anxiety, and had a sharpened memory, an excellent sense of humor and a capacity for imitation. Certain stimuli resulted in panic and they drew violent pictures, such as moving buses, groups of people and barking dogs with high volume of noise. In circumstances of high stress, they showed self mutilation behavior. At the time this paper was written, they attended a school for special education and showed good interpersonal relationships. They did not use any medications to reduce the characteristic symptoms of FXS.

Similar conditions were observed in members of the maternal family of the twins. All the collected data for the construction of a diagnostic genealogy were based solely on the reports of the twins' mother, but they seem to a priori corroborate the behavior and characteristics seen in FXS. In the descriptive genealogy of this family, the maternal grandfather had behavior typical of FXS and was very similar to the twins, suggesting that he could be the bearer of a pre-mutation FMR 1 gene. If this is true, then $100 \%$ of the daughters of this carrier would carry a pre-mutation for the FMR 1 gene. Consequently, some members of the third generation could be affected by the fragile $\mathrm{X}$ syndrome. Of the 8 daughters of this carrier who generated grandsons, 6 seem have had descendants with this same anomaly. It was also verified that all possible female carriers of the pre-mutation in this family showed premature ovarian insufficiency, a circumstance that results in precocious menopause.

During the external physical examination of the patients, it was observed that they had a long face and prominent ears. In the intrabucal examination, one twin cooperated for a short period of time, and it was observed that he possessed macroglossia, mandible prognathism, ogival palate, top bite, a normal aspect of mu- 
cosa, many teeth with cavities and a fracture of the mesial angle of element 21 caused by trauma. Curiously, the same problem was observed in his brother (Figure 2).

Because of the limited capacity for cooperation by the patients, the professional team opted to perform the dental treatment under intravenous sedation. The patients had been evaluated by the medical anesthetist and, after detailed anamnesis, a routine physical examination of both twins, the patients were considered healthy enough to submit to such a procedure.

First, pre-sedation using midazolan maleate (Dormonid $^{\circledR}$, Roche, São Paulo, Brazil) via the nose $(0,5$ $\mathrm{mg} / \mathrm{kg}$ ) was administered. After 20 minutes, intravenous intubation was carried out to maintain the venous access and to apply a 5\% isotonic glucose solution for replacement. To keep the oral cavity dry and to prevent cardiac arrest, oxygen and atropinization was adapted to be delivered via the nasal cavity. For sedation, propofol (Diprivan $^{\circledR}$, Astra Zeneca of Brazil Ltda., São Paulo, Brazil) and fentanyl citrate $\left(\right.$ Fentanil $^{\circledR}$, Pharmaceutical Janssen-Cilag, São Paulo, Brazil) were continuously infused.

During the operation, the cardio-respiratory condition of the patients was monitored by an oximeter and electrocardiography. A defibrillator device was available during the whole procedure for use in case of cardiac fibrillation by the patients.

For the dental procedures, photopolymerized resin was used to restore the anterior teeth, amalgam in the posterior teeth and exodontia of elements that had a doubtful diagnosis (Figure 3). After the dental treatment, a recovery period was initiated. The postoperative recommendations to the parents about diet and the ingestion of antihemetics and analgesics were made, as well as instructions regarding correct oral hygiene, diet and the importance of regular visits to the clinic for dental maintenance and the oral health of the patients.

\section{DISCUSSION}

The twins' behavior was observed with special interest, due to the presence of some pertinent FXS symptoms such as hyperactivity, poor vision, problems with speech, anxiety, sharpened memory, a sense of humor, the capacity for imitation and situations of panic and violence. Such behavior is described by some researchers as typical of individuals with the fragile $X$ syndrome [20].

Treatments for any individual with fragile $\mathrm{X}$ syndrome is only efficient when combined with therapeutic counseling, special education and medications in accordance with the special needs of each patient. The relative aspects of the behavior observed in the described pa- tients must be considered as genuine symptoms as they do not use, until now, any medications or participate in specific therapies to limit the psychopathologic symptoms related to this condition.

In the pre-pubertal phase of development, the phenoltypic characteristics of patients carrying the fragile $\mathrm{X}$ syndrome do not always show the condition and are therefore not easy to identify [2]. Although the twins descrybed in our study fall into this category, it was still possible to observe the extended face and large ears, corroborating the clinical findings published previously [17].

The hypoplasia of dental enamel is described as an important fact and related to the fragile $\mathrm{X}$ syndrome [15, $16]$, but it was not possible to correlate such facts in our clinical case.

Intravenous sedation was selected to help with the dental intervention of the patients, as it had results that were appropriate for the treatment. This facilitated the accomplishment of the dental procedures and improved the quality of the treatment as the twins had a limited ability to cooperate. It was possible also to reduce the anxiety provide greater comfort to the patients [19].

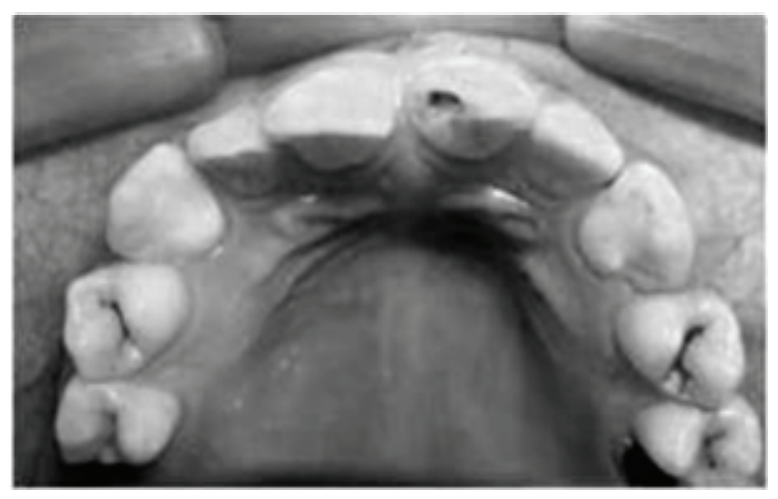

Figure 2. Intra-oral view of one patient.

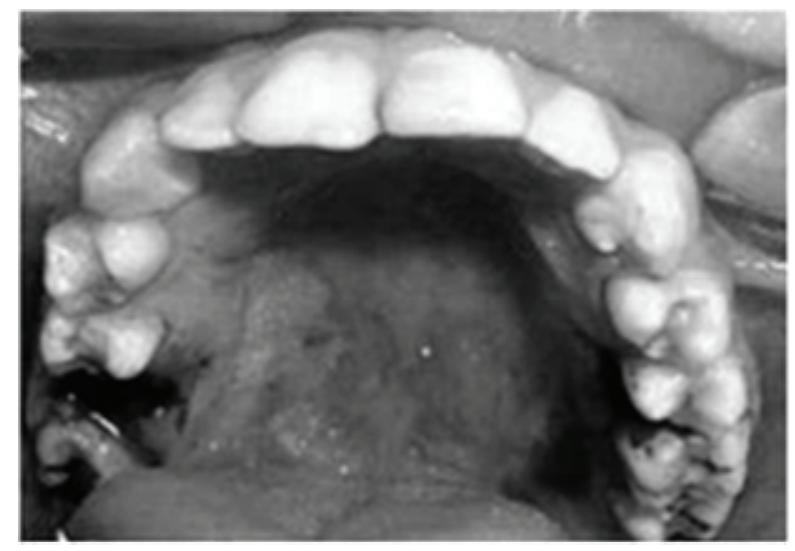

Figure 3. Completed dental treatment of the same patient. 
The timing of dental treatment for an individual with fragile $\mathrm{X}$ syndrome must be designed for each specific case. The severity of mental retardation and the level of potential cooperation are factors that can compromise the treatment success. In situations that necessitate extreme measures, these must be opted for even if it means intravenous sedation or general anesthesia. It is interesting to observe and identify the stimuli that can cause positive or negative reactions in patients, initiating a patient into a plan of treatment with individually appropriate and complete dental procedures $[17,19]$.

The approach to these patients should always occur in a multidisciplinary manner, with the participation of anesthetist, cardiologist, psychiatrist, speech therapist, physiotherapist and psychologist.

The greatest difficulty in the treatment of these individuals is the presence of mental disability. In these cases autistic demonstrations, aggressiveness or anxiety require specific care because the patient might need medications. Thus, the patient's physician should always be consulted regarding medications in order to avoid possible interaction with drugs used in the dental treatments. In a similar manner, patients with heart disease, which is characteristics of the syndrome, should be evaluated carefully and the possibility of using antibiotic prophylaxis for dental interventions that might release bacteria must be considered.

\section{CONCLUSIONS}

- This paper provides information regarding the characteristic manifestations of Fragile $\mathrm{X}$ syndrome not only aided in the handling of the patients but also enabled us to develop clinical programs to promote and maintain oral health using individualized and specific dental procedures.

- The course of dental treatment in an individual affected by FXS must be designed specifically in each case as it is necessary to be aware of the implications that might interfere with normal dental practices.

- The severity of mental retardation and the degree of behavioral problems are factors that can compromise the success of dental treatment. In situations where it is necessary to use auxiliary methods, the completion of the dental procedure dental might require intravenous sedation techniques or even general anesthesia.

- In the present study, the twins exhibited mental retardation and a certain lack of cooperation. Nevertheless, since both exhibited only carious lesions and a fracture of the incisor, treatment under sedation was planned and conducted out of a hospital unit.

- The identification of individuals affected by Fragile $\mathrm{X}$ syndrome, through accurate diagnosis, allows the families of these patients to investigate and evaluate the risks of transmission of this genetic abnormality. Through appropriate genetic counseling it is possible to identify other relatives who are at risk of having inherited the altered gene FMR 1 and thus make it possible to identify family members that might be pre-mutation carriers before it is transmitted as a full mutation to their offspring.

\section{REFERENCES}

[1] Willemsen, R., Olmer, R., Otero, Y.D.D. and Oostra, B.A. (2000) Twin sisters, monozygotic with the fragile $X$ mutation, but with a different phenotype. Journal of Medical Genetics, 37(4), 603-604.

[2] D'Hust, C. and Kooy, R.F. (2009) Fragile X syndrome: From molecular genetics to therapy. Journal of Medical Genetics, 46(9), 577-584.

[3] Chatterjee, S., Maitra, A., Kadam, S., Patel, Z., Gokral, J. and Meherji, P. (2009) CGG repeat sizing in the FMR1 gene in Indian women with premature ovarian failure. Reprod Biomed Online, 19(4), 281-286.

[4] Behery, A.K. (2008) Fragile X-syndrome: Clinical and molecular studies. Journal of the Egyptian Public Health Association, 83(3-4), 273-283.

[5] Spencer, C.M., Serysheva, E., Yuva-Paylor, L.A., Oostra, B.A., Nelson, D.L. and Paylor, R. (2006) Exaggerated behavioral phenotypes in Fmr1/Fxr2 double knockout mice reveal a functional genetic interaction between Fragile X-related proteins. Human Molecular Genetics, 15(12), 1984-1994.

[6] Coffee, B., Keith, K., Albizua, I., Malone, T., Mowrey, J., Sherman, S.L. and Warren, S.T. (2009) Incidence of fragile X syndrome by newborn screening for methylated FMR1 DNA. American Journal of Human Genetics, 85(4), 503-514.

[7] Sung, Y.J., Conti, J., Currie, J.R., Brown, W.T. and Denman, R.B. (2000) RNAs that interact with the fragile X syndrome RNA binding protein FMRP. Biochemical \& Biophysical Research Communications, 275(3), 973-980.

[8] Schaeffer, C., Beaulande, M., Ehresmann, C., Ehresmann, B. and Moine, H. (2003) The RNA binding protein FMRP: New connections and missing links. Biology of the Cell, 95(3), 221-228.

[9] Rueda, J.R., Ballesteros, J. and Tejada, M.I. (2009) Systematic review of pharmacological treatments in fragile X syndrome. BioMedCentral Neurology, 9, 53.

[10] Verhelj, C., Bakker, C.E., Graaff, E., Keulemans, J., Willemsen, R., Verkerk, A.J.M.H., Galjaard, H., Reuser, A.J.J., Hoogeveen, A.T. and Oostra, B.A. (1993) Characterization and localization of the FMR-1 gene product associated with fragile $\mathrm{X}$ syndrome. Nature, 363(6431), 722-724.

[11] Kooy, R.F., Willensen, R. and Oostra, B.A. (2000) Fragile $\mathrm{X}$ syndrome at the turn of the century. Molecular Medicine Today, 6(5), 193-198.

[12] Enriquez, E., Moreno, R., Barra, F., Curotto, M.B., Alliende, R., Anriquez, E., Barahona, G. and Muzzo, S. (1983) Fragile X syndrome: report of the 1st case confirmed cytogenetically in Chile. Revista Chilena de Pediatría, 54(6), 410-416. 
[13] Nunn, J.H. and Durning, P. (1990) Fragile X (Martin Bell) syndrome and dental care. British Dental Journal, 168(4), 160-162.

[14] Kulkarni, G. and Levine, N. (1994) Fragile X (MartinBell) syndrome. Special Care Dentistry, 14(1), 21-25.

[15] Bilgen, T., Keser, I., Mihci, E., Haspolat, S., Tacoy, S. and Luleci, G. (2005) Molecular analysis of fragile X syndrome in Antalya Province. Indian Journal of Medical Sciences, 59(4), 150-155.

[16] Magalhães, M.H.C.G., Faria, A.D.A., Bueno, D.F. and Pereira, M.C. (1998) Dental aspects of fragile X syndrome - report of two clinical cases. Revista da PósGraduação USP, 5, 192-196.

[17] Sheldon, L. and Turk, J. (2000) Monozygotic boys with fragile X syndrome. Developmental Medicine \& Child Neurology, 42(11), 768-774.
[18] Loesch, D.Z., Litewka, L., Churchyard, A., Gould, E., Tassone, F. and Cook, M. (2007) Tremor/ataxia syndrome and fragile X premutation: Diagnostic caveats. Journal of Clinical Neuroscience, 14(3), 245-248.

[19] McConkie-Rosell, A., Abrams, L., Finucane, B., Cronister, A., Gane, L.W., Coffey, S.M., Sherman, S., Nelson, L.M., Berry-Kravis, E., Hessl, D., Chiu, S., Street, N., Vatave, A. and Hagerman, R.J. (2007) Recommendations from multi-disciplinary focus groups on cascade testing and genetic counseling for fragile $\mathrm{X}$ - associated disorders. Journal of Genetic Counseling, 16(5), 593-606.

[20] Forrest, L.E., Curnow, L., Delatycki, M.B., Skene, L. and Aitken, M. (2008) Health first, genetics second: Exploring families' experiences of communicating genetic information. European Journal of Human Genetics, 16(11), 1329-1335. 